\title{
Prenatal ultrasonography and Doppler sonography for the clinical investigation of isolated ventricular septal defects in a late second-trimester population
}

Wei-Hsiu Chiu ${ }^{1,2,3 \dagger}$, Ming-Chon Hsiung ${ }^{4 \dagger}$, Ran-Chou Chen ${ }^{1,5+}$, Xiao-Min Xiao ${ }^{2}$, Cai-Lin Wu ${ }^{6}$ and Tao-Hsin Tung ${ }^{7,{ }^{*}}$

\begin{abstract}
Background: The purpose of this study was to evaluate the efficacy of prenatal ultrasonography and Doppler sonography in detecting isolated ventricular septal defects (VSDs) in a late-second-trimester population.

Methods: Fetal echocardiography, Doppler ultrasound, and biometry were used to evaluate 2,661 singleton fetuses (1,381 male fetuses and 1,280 female fetuses) between 1 August 2006 and 31 May 2010. The efficacy of each fetal biometry, Doppler ultrasound, and nasal bone length (NBL) measurement was evaluated in all of the fetuses. A standard fetal echocardiographic evaluation, including two-dimensional gray-scale imaging and color and Doppler color flow mapping, was performed on all fetuses.

Results: We detected isolated VSDs in 124 of the 2,661 singleton fetuses between 19 and 24 weeks of gestation. The prevalence of isolated VSDs in the study population was 4.66\%. A multiple logistic regression analysis indicated that short fetal NBL (odds ratio $=0.691,95 \%$ confidence interval: 0.551 to 0.868 ) and the pulsatility index (PI) of the umbilical artery (odds ratio $=8.095,95 \%$ confidence interval: 4.309 to 15.207 ) and of the middle cerebral artery (odds ratio $=0.254,95 \%$ confidence interval: 0.120 to 0.538 ) are significantly associated with isolated VSDs.

Conclusion: Late-second-trimester fetal NBL, umbilical artery PI, and middle cerebral artery PI are useful parameters for detecting isolated VSDs, and can be used to estimate the a priori risk of VSDs in women at high risk and at low risk of isolated VSDs.
\end{abstract}

Keywords: Ultrasonography, Ventricular septal defects, Second trimester

\section{Background}

Prenatal ultrasound screening is widely employed for detecting congenital malformations and structural heart defects. In previous studies, the prevalence of fetal congenital heart disease (CHD) ranged from 3/1,000 to 10/1,000 total live births. In the presence of CHD, ventricular septal defects (VSDs) are highly prevalent in newborns [1-3]. VSDs account for 30 to $35 \%$ of all CHD detected after birth. Previous studies have identified a

\footnotetext{
*Correspondence: ch2876@chgh.org.tw

${ }^{\dagger}$ Equal contributors

${ }^{7}$ Department of Medical Research and Education, Cheng Hsin General Hospital, No. 45, Cheng-Hsin Street, 112 Taipei, Taiwan

${ }^{8}$ Faculty of Public Health, School of Medicine, Fu-Jen Catholic University, 24205 New Taipei City, Taiwan

Full list of author information is available at the end of the article
}

VSD prevalence of 10 to $16 \%$ in fetal tests [1,4,5]. VSDs were also associated with other heart structural defects, such as right ventricular outflow tract and left ventricular outflow tract anomalies, as well as some aspects of Tetralogy of Fallot. Chromosomal anomalies associated with a VSD include trisomies 21,13 , and 18, deletion in 22q11, and nonchromosomal malformed fetuses [6,7].

The incidence of VSDs is the highest and second highest in live births and stillbirths, respectively [1]. VSDs are also the most common CHD diagnosis within the first year of life and the most frequently detected prenatal heart defect. VSDs represent one of the major sources of false-negative diagnoses in the uterus. Improvements in prenatal screening and VSD diagnosis can reduce neonatal mortality and morbidity $[8,9]$. B-mode fetal echocardiography as 
well as M-mode and color-mode echocardiography are the clinical screening methods used for VSDs [10-12]. Previous studies have proposed fetal Doppler echocardiography screening as an additional screening tool for VSDs [13-15]. Other studies indicated a high correlation between results obtained using fetal echocardiography and color Doppler echocardiography, reporting high sensitivity and specificity, and a low false-positive rate for CHD in fetal echocardiography examinations [16-19]. Conducting Doppler assessments of fetal arterial blood flow might increase the rate of identification of fetuses at risk of CHD. According to previous studies, CHD is associated with a significantly decreased pulsatility index (PI) in the middle cerebral artery (MCA) and an increased PI in the umbilical artery (UA) [20-22].

Fetal VSD assessment is a major component of a prenatal fetal heart examination, and is a useful primary diagnostic and screening tool for fetal CHD or chromosomal anomalies. In this study, we investigated fetal variations in VSDs using fetal arterial Doppler assessments to establish the risk of fetal VSDs in the general population.

\section{Methods \\ Study participants}

The study participants were 2,661 women with singleton pregnancies who underwent a fetal level II prenatal ultrasound examination, including detailed fetal echocardiography, in one teaching hospital and three obstetric clinics in Taipei, Taiwan between August 2006 and May 2010. As part of their prenatal care routine, all women underwent a prenatal ultrasound (including echocardiography) at 32 to 34 weeks of gestation. All procedures were performed in accordance with the guidelines of our institutional ethics committee and the tenets of the Declaration of Helsinki. All patient information was anonymous. Access to personal records was approved by the Hospital Human Subjects Review Board at Fu-Jen University, Taipei, Taiwan.

The gestational age (GA) of a fetus was determined according to the date of confinement estimated by the patient. If the estimated date of confinement was unknown, the difference between the ultrasonically estimated GA and the determined GA was assumed to be $<10$ days. For all fetuses with any associated abnormality, an antenatal diagnosis was arranged at a medical center within 1 to 2 weeks. The study exclusion criteria included a previous history of chromosome abnormalities, fetal structural anomalies or other $\mathrm{CHD}$, and maternal complications.

\section{Ultrasound equipment and intraobserver variability}

All fetal examinations were performed using a Voluson730ProV ultrasound platform (General Electric Medical Systems, Milwaukee, WI, USA) with multifrequency transabdominal transducers. A single experienced registered sonographer collected all scans and fetal measurements.
Reliability statistics were used to assess the agreement of intraobserver reliability among repeated fetal biometry measurements collected by the same examiner.

\section{Measurement of fetal nasal bone and biometric examination}

Fetal nasal bone length (NBL) was measured in a midsagittal view of the head using appropriate image magnification. To prevent measurement error, if the nasal bone was absent or shortened then the angle of the fetal nose was maintained at between $45^{\circ}$ and $135^{\circ}$. Each increment was set at a $0.1 \mathrm{~mm}$ caliper distance, at the appropriate image magnification, to maintain accuracy [23].

The biparietal diameter (BPD) was measured on a transverse axial section of the fetal head, which included the midline falx and the thalami, symmetrically positioned on either side of the falx from the outer edge of the nearer parietal bone to the inner edge of the more distant parietal bone, and the septum pellucidum was visualized at onethird of the frontal-occipital distance [24].

The plane of the abdominal circumference (AC) was measured on a transverse section through the fetal abdomen. This plane was at the level of the liver and stomach bubble including the ductus venosus within the point of bifurcation of the main portal vein into its right and left branches in the anterior third of the fetal abdomen in the axial plane $90^{\circ}$ to the fetal spine and posterior to the aorta. Measured from skin to skin, the transverse and anteriorposterior diameters were first measured as the long or short axis of an onscreen ellipse, and the circumference was obtained using elliptical calipers superimposed on the four points [24]. The single measurement plane of six limb bones (humerus, ulna, radius, femur, tibia, and fibula) was on the longest section of each structure. An appropriate magnification was used for the image to occupy threequarters of the screen. The transducer was aligned to the long axis of the limb bone to obtain the appropriate plane of the section. The ossified portion of diaphysis was measured. The cartilaginous ends of the limb bones were excluded [25].

The estimated fetal body weight (FBW) was calculated using Hadlock's formula [26]. This formula involves a summation of the BPD, AC, and femur length and provides a number in millimeters. The regression equation of the estimated FBW is:

$$
\begin{aligned}
\log _{10}(\mathrm{FBW})= & 1.4787-0.003343(\mathrm{AC} \times \mathrm{FL}) \\
& +0.001837(\mathrm{BPD})^{2}+(0.0458 \times \mathrm{AC}) \\
& +(0.158 \times \text { femur length })
\end{aligned}
$$

\section{Fetal heart assessment and Doppler measurement}

The sonographers performed detailed fetal echocardiographic examinations of the 19-week to 24-week level II 
scans, under the direct supervision of an obstetrician. The detailed fetal heart assessment included basic screening and an extended cardiac scan [27,28]. The standard fetal echocardiographic evaluation involves employing all modalities of diagnostic ultrasound, including twodimensional gray-scale imaging, and color and Doppler color flow mapping. The examination included the standard four-chamber view, the views of the left ventricular outflow tract and right ventricular outflow tract, the three-vessel view, and the basal short-axis two-dimensional B-mode echocardiography image.

Gray-scale imaging was initially performed, followed by color Doppler flow mapping (Figure 1). The high-pass filter was set at $100 \mathrm{~Hz}$. The four-chamber view was observed using real-time scanning, and color Doppler was used to detect the presence of a VSD during the phase of a shunt between the right and left ventricles (Figure 2). The fetuses with VSDs that shunted flow were detected using two-dimensional color Doppler ultrasound examinations. The VSDs were recorded to ensure that the septum was perpendicular to the ultrasound beam, enabling the flow crossing the septum, indicating a septal defect, to be detected accurately [29]. For all fetuses with VSDs, a diagnostic antenatal echocardiographic examination was arranged at a medical center within 1 to 2 weeks. After delivery, the newborn babies with VSDs received a postnatal echocardiographic examination. In the non-VSD group, a prenatal ultrasound (including echocardiography) was performed at 32 to 34 weeks of gestation. A pediatrician examined the heart sound of all newborn babies.

An ultrasound examination for fetal biometry and a fetal heart assessment were conducted to exclude structural abnormalities. Liquor volume assessments, Doppler blood flow measurements of the UA, and Doppler blood flow velocity measurements of the MCA were also performed. All fetuses were subjected to Doppler examination of the MCA. An axial section of the brain,

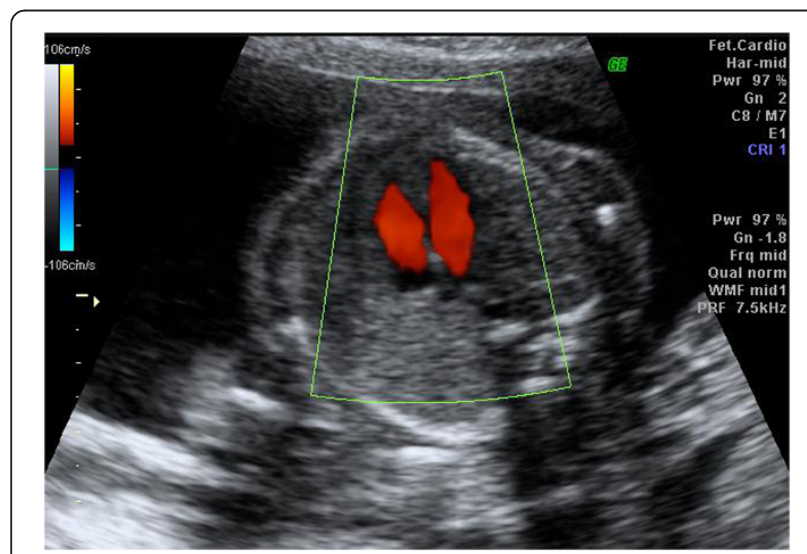

Figure 1 Color Doppler flow mapping.

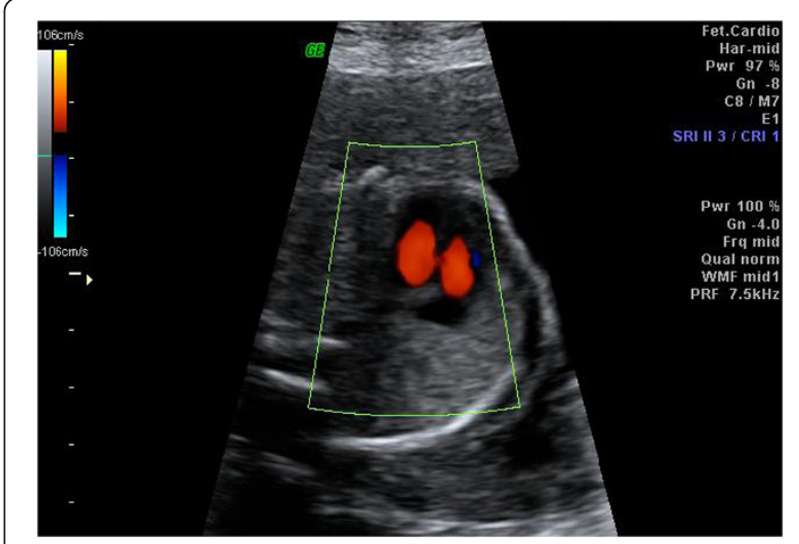

Figure 2 Shunt between the right and left ventricles.

imaged in the BPD biometry plane, was obtained. The plane was then shifted downward toward the skull base. The circle of Willis was visualized and the MCA on one side was examined. The optimal site for recording a Doppler spectrum is the midpoint of the MCA, approximately $1 \mathrm{~cm}$ from the circle of Willis. The width of the sample volume was set between 2 and $4 \mathrm{~mm}$. The wall filter was set as $\leq 120 \mathrm{~Hz}$. Pulsed wave Doppler analysis was performed with the angle between the ultrasound beam and the direction of blood flow maintained as close to 0 to $25^{\circ}$ as possible (Figure 3) [30,31]. The Doppler spectrum was sampled from a free loop of the umbilical cord with a wall filter setting $>120 \mathrm{~Hz}$ (Figure 4) [30]. The PIs and resistance indices (RIs) of the UA and MCA Doppler waveform were measured.

In this study, the sensitivity of UA PIs $>90 \%$ (1.47), MCA PIs <10\% (1.23) and nasal bone length were $36.80 \%$, $20.80 \%$ and $19.35 \%$, respectively. The specificity of UA PIs $>90 \%$ (1.47), MCA PIs <10\% (1.23), and nasal bone length were $96.71 \%, 91.52 \%$, and $93.46 \%$, respectively.

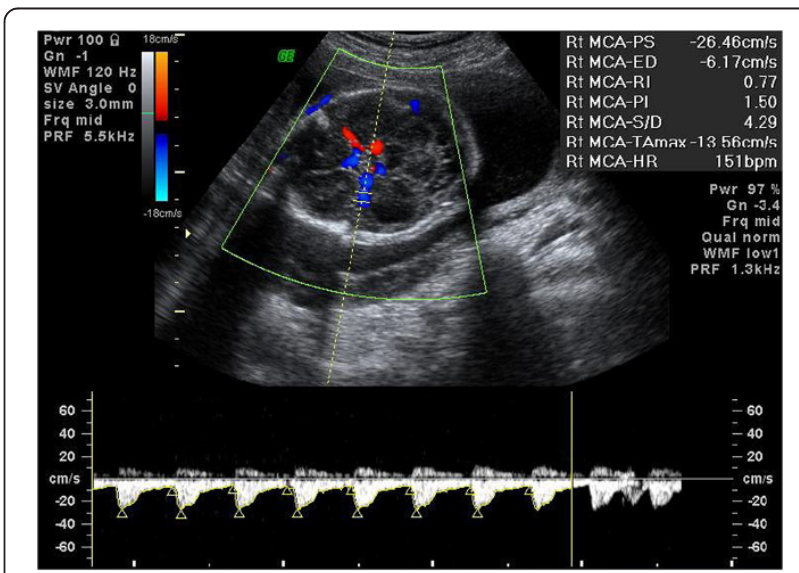

Figure 3 Middle cerebral artery. 


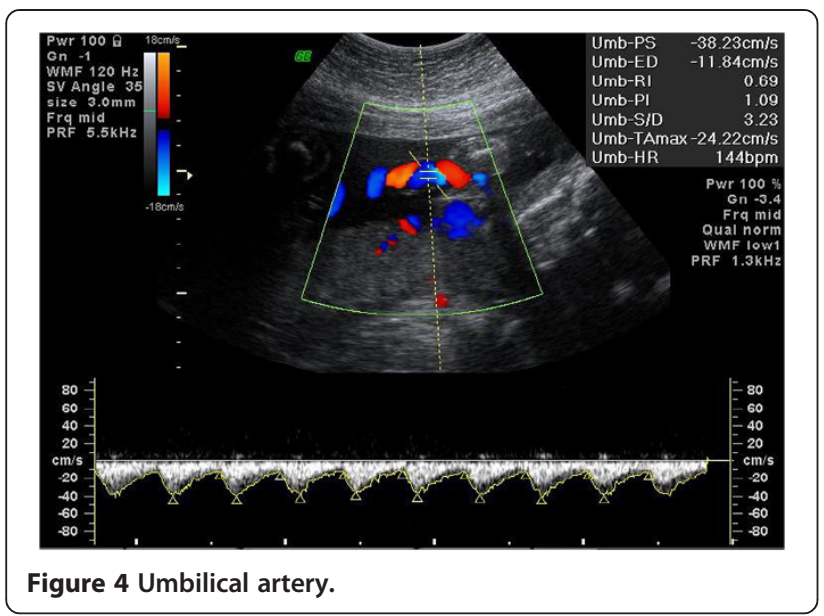

\section{Data analysis}

A statistical analysis was performed using the Statistical Package for the Social Sciences (Version 13.0 for Windows; SPSS, Chicago, IL, USA). $P<0.05$ was considered statistically significant. The mean, standard deviation, and percentiles of the GA, NBL, limb bone length, estimated FBW, cardiothoracic area ratio, cardiothoracic circumference ratio, PIs and RIs of the UA, and PIs and RIs of the MCA were determined. In addition, a logistic regression of a binary response variable $(Y)$ on a continuous, normally distributed variable $(X)$ with a sample size of 2,661 observations achieves $99 \%$ power at a 0.05 significance level to detect a change in $\operatorname{Prob}(Y=1)$ from the value of 0.046 at the mean of $X$ to 0.067 when $X$ is increased to one standard deviation above the mean [32].

\section{Results and discussion}

In this study, we evaluated 60 fetuses randomly selected during ultrasound screening. Table 1 presents the mean differences between the measurements collected using prenatal ultrasonography and Doppler sonography, and the accepted Cronbach's alpha values. Except VSDs, we excluded 43 cardiac anomaly cases. The prevalence of all cardiac anomalies was $6.17 \%$ in our cohort. Because most of the parameters in studies change with gestational age, Table 2 presents the distribution of parameters as multiples of medians.

As shown in Table 3, the overall prevalence of VSDs in the screened population was $4.66 \%$. A chi-square test indicated that the prevalence of VSDs exhibited a borderline statistically significant decrease as the GA increased $(P=0.06)$. The prevalence of VSDs in the male and female fetuses showed nonsignificant differences ( $4.85 \%$ vs. $4.45 \%, \chi^{2}=0.15, P=0.70$ ). After stratifying the data on GA into six age groups, the male fetuses exhibited a higher prevalence of VSDs than the female fetuses did in all GA groups except the 19-week to 23-week subgroup. The chi-square test indicated that the GA-specified prevalence of VSDs was significantly associated with age in the male $(P=0.04)$, but not the female $(P=0.38)$, fetuses.

Table 4 presents the characteristics of the fetuses with and without VSDs in the late-second-trimester population. Using the two-sample independent $t$ test, we identified that the GA, NBL, BPD, AC, femur length, tibia length, fibula length, humerus length, ulna length, radius length, estimated FBW, UA PI, UA RI, MCA PI, MCA RI, ratio of the MCA RI to UA PI, and ratio of MCA RI to UA RI were all significantly associated with VSDs.

We then used a multiple logistic regression model to evaluate the effects of independent associated risk factors on VSDs. Table 5 presents the NBLs (odds ratio $=0.69,95 \%$ confidence interval: 0.55 to 0.87 ), UA PIs (odds ratio $=8.10$, 95\% confidence interval: 4.31 to 15.21 ), and MCA PIs (odds

Table 1 Intraobserver repeatability of fetal biometry and Doppler assessment

\begin{tabular}{|c|c|c|c|c|c|}
\hline & $n$ & Repeat measurements & Mean difference & SE & Cronbach's a value \\
\hline Nasal bone length & 60 & 2 & -0.0033 & 0.06369 & 0.999 \\
\hline Biparietal diameter & 44 & 2 & -0.0591 & 0.13224 & 0.997 \\
\hline Head circumference & 44 & 2 & 0.1682 & 0.12055 & 0.999 \\
\hline Humerus length & 44 & 2 & 0.1045 & 0.06950 & 0.999 \\
\hline Radius length & 44 & 2 & 0.0523 & 0.07045 & 0.998 \\
\hline Ulna length & 44 & 2 & 0.0182 & 0.08455 & 0.998 \\
\hline Femur length & 44 & 2 & 0.1182 & 0.07557 & 0.999 \\
\hline Tibia length & 44 & 2 & 0.0318 & 0.06950 & 0.999 \\
\hline Fibula length & 44 & 2 & 0.0295 & 0.08636 & 0.998 \\
\hline UA PI & 60 & 2 & 0.0017 & 0.01659 & 0.999 \\
\hline UA RI & 60 & 2 & 0.0010 & 0.00986 & 0.997 \\
\hline MCA PI & 60 & 2 & -0.0030 & 0.01816 & 0.997 \\
\hline MCA RI & 60 & 2 & 0.0003 & 0.00367 & 0.999 \\
\hline
\end{tabular}

MCA, middle cerebral artery; PI, pulsatility index; RI, resistance index; SE, standard error (difference in the paired measurements); UA, umbilical artery. 
Table 2 Distribution of study parameters (multiples of medians)

\begin{tabular}{|c|c|c|c|c|c|c|}
\hline & 19 weeks & 20 weeks & 21 weeks & 22 weeks & 23 weeks & 24 weeks \\
\hline Nasal bone length & 0.96 & 0.93 & 0.95 & 0.96 & 0.92 & 0.90 \\
\hline Biparietal diameter & 0.94 & 0.99 & 0.98 & 0.99 & 0.99 & 0.97 \\
\hline Head circumference & 0.97 & 0.98 & 0.98 & 0.99 & 0.99 & 0.98 \\
\hline Abdominal circumference & 1.00 & 0.99 & 0.98 & 0.96 & 0.99 & 0.99 \\
\hline Femur length & 0.99 & 0.94 & 0.97 & 0.97 & 1.00 & 0.98 \\
\hline Tibia length & 0.98 & 0.97 & 0.97 & 0.98 & 0.99 & 0.97 \\
\hline Fibula length & 1.00 & 0.97 & 0.97 & 0.98 & 0.99 & 0.97 \\
\hline Humerus length & 0.95 & 0.99 & 0.99 & 0.98 & 0.97 & 0.98 \\
\hline Radius length & 0.99 & 0.96 & 0.98 & 0.98 & 0.98 & 0.95 \\
\hline Ulna length & 1.00 & 0.99 & 0.99 & 0.99 & 0.99 & 0.97 \\
\hline Estimated FBW & 0.97 & 0.96 & 0.96 & 0.94 & 0.97 & 0.99 \\
\hline UA PI & 1.60 & 1.06 & 1.04 & 1.06 & 1.06 & 1.06 \\
\hline UA RI & 1.22 & 1.05 & 1.03 & 1.03 & 1.01 & 1.03 \\
\hline MCA PI & 0.88 & 0.95 & 0.98 & 0.90 & 0.92 & 0.89 \\
\hline MCA Rl & 0.94 & 1.00 & 0.99 & 0.96 & 0.98 & 0.96 \\
\hline MCA/UA PI ratio & 0.61 & 0.93 & 0.99 & 0.88 & 0.99 & 0.99 \\
\hline MCA/UA RI ratio & 0.77 & 0.98 & 1.00 & 0.95 & 0.96 & 0.98 \\
\hline
\end{tabular}

FBW, fetal body weight; MCA, middle cerebral artery; MCA/UA PI ratio, ratio of middle cerebral artery resistance index to umbilical artery pulsatility index; MCA/UA $\mathrm{RI}$ ratio, ratio of middle cerebral artery resistance index to umbilical artery resistance index; $\mathrm{PI}$, pulsatility index; $\mathrm{RI}$, resistance index; $\mathrm{UA}$, umbilical artery.

ratio $=0.25,95 \%$ confidence interval: 0.12 to 0.54 ) following adjustment for confounding factors.

Other independent variables included the GA, NBL, BPD, AC, femur length, tibia length, fibula length, humerus length, ulna length, radius length, estimated FBW, UA PIs, UA RIs, MCA PIs, MCA RIs, ratio of the MCA RI to UA PI, and ratio of MCA RI to UA RI, excepting the cardiothoracic area ratio and cardiothoracic circumference ratio.

According to our research, few studies have evaluated the parameters of circulation in fetuses with VSDs in Taiwan. Therefore, the purposes of our study were to evaluate the effects of isolated VSDs on fetal arterial hemodynamics and to determine the prognostic value of fetal arterial Doppler sonography in fetuses with VSDs. The prevalence of intrauterine growth restriction in the VSD and non-VSD groups was estimated as $4.84 \%$ and $4.46 \%$, respectively. These results implied that fetuses with isolated VSDs were significantly smaller than the fetuses with normal cardiac anatomy. In addition, our study results indicated that the hemodynamics of the UA and MCA in all fetuses with CHD differed significantly from those of healthy fetuses. These findings support those of previous studies [20-22]. However, from a clinical viewpoint, abnormal UA PIs, UA RIs, MCA PIs, and MCA RIs are no more frequent in fetuses with isolated VSDs than in healthy fetuses. Our results indicated that the UA PI and the MCA PI represent risk factors for fetal VSDs. This finding is consistent with those of other population-based studies [20,22,33].

In this study, the fetuses with VSDs exhibited significantly lower values for fetal biometry and FBW than did the fetuses without VSDs. In Mari and Deter's study, reductions in the fetal MCA PI were associated with perinatal growth restriction [34]. Lower fetal MCA PI values indicate that the human fetus responds to hypoxemia by centralizing blood flow to the brain in a process known as the brain-sparing effect [35]. A sequence of hemodynamic changes occurs as the fetal condition progressively deteriorates; however, the precise nature of these changes has not been fully elucidated.

Our study results indicated that the risk of fetal VSDs decreases with the degree of NBL shortening. VSDs are the most common lesion in trisomy 21; therefore, identifying fetal VSDs might increase the identification rate of fetuses at risk of developing Down syndrome [36]. Down syndrome is strongly associated with the hypoplastic fetal NBL, and fetal NBL examination is associated with high sensitivity, high specificity, and a low false-positive rate in Down syndrome screening [37,38]. In this study, we followed up the infants with VSDs for 24 months. Most of the infants' VSDs were spontaneous closures between 6 and 18 months, and $28.6 \%(36 / 124)$ of the cases were spontaneous closures after delivery. In previous studies, the incidence of live-born infants with VSDs ranged from approximately 1 to $4.36 \%[39,40]$. In addition, the 
Table 3 Gender and gestational age specific prevalence of ventricular septal defects among screened subjects $(n=2,661)$

\begin{tabular}{|c|c|c|c|c|c|c|c|c|c|c|c|c|c|}
\hline \multirow[t]{2}{*}{ GA (weeks) } & \multicolumn{4}{|r|}{ Male } & \multicolumn{4}{|r|}{ Female } & \multicolumn{4}{|r|}{ Total } & \multirow[b]{2}{*}{$\begin{array}{l}P \text { value for } \\
\text { trend test }\end{array}$} \\
\hline & & Screened $(n)$ & $\operatorname{VSD}(n)$ & Prevalence (\%) & $\begin{array}{r}P \text { value for } \\
\text { trend test }\end{array}$ & Screened $(n)$ & $\operatorname{VSD}(n)$ & Prevalence (\%) & $\begin{array}{l}P \text { value for } \\
\text { trend test }\end{array}$ & Screened $(n)$ & VSD $(n)$ & Prevalence (\%) & \\
\hline $19^{+0}$ to $19^{+6}$ & 34 & 0 & 0.00 & & 48 & 4 & 8.33 & & 82 & 4 & 4.87 & & \\
\hline $20^{+0}$ to $20^{+6}$ & 182 & 11 & 6.04 & 0.04 & 170 & 7 & 4.12 & 0.38 & 352 & 18 & 5.11 & 0.06 & \\
\hline $21^{+0}$ to $21^{+6}$ & 338 & 24 & 7.10 & & 284 & 11 & 3.87 & & 622 & 35 & 5.63 & & \\
\hline $22^{+0}$ to $22^{+6}$ & 382 & 20 & 5.23 & & 340 & 17 & 5.00 & & 722 & 37 & 5.12 & & \\
\hline $23^{+0}$ to $23^{+6}$ & 263 & 7 & 2.66 & & 270 & 15 & 5.56 & & 533 & 22 & 4.13 & & \\
\hline $24^{+0}$ to $24^{+6}$ & 182 & 5 & 2.74 & & 168 & 3 & 1.79 & & 350 & 8 & 2.29 & & \\
\hline Total & 1,381 & 67 & 4.85 & & 1,280 & 57 & 4.45 & & 2,661 & 124 & 4.66 & & \\
\hline
\end{tabular}

GA, gestational age; VSD, ventricular septal defect. 
Table 4 Characteristics of ventricular septal defect (VSD) among screened subjects $(n=2,661)$

\begin{tabular}{|c|c|c|c|c|c|}
\hline \multirow[t]{2}{*}{ Variable } & \multicolumn{2}{|c|}{ Normal $(n=2,537)$} & \multicolumn{2}{|c|}{ VSD $(n=124)$} & \multirow[t]{2}{*}{$P$ value } \\
\hline & Mean \pm SD & 10 to $90 \%$ & Mean \pm SD & 10 to $90 \%$ & \\
\hline $\mathrm{NBL}(\mathrm{mm})$ & $6.74 \pm 0.87$ & 5.60 to 7.90 & $6.40 \pm 0.79$ & 5.30 to 7.40 & $<0.0001$ \\
\hline $\mathrm{BPD}(\mathrm{mm})$ & $54.33 \pm 9.10$ & 48.00 to 60.00 & $52.65 \pm 4.87$ & 47.12 to 59.70 & 0.041 \\
\hline $\mathrm{HC}(\mathrm{mm})$ & $197.34 \pm 15.57$ & 177.00 to 218.00 & $193.94 \pm 14.66$ & 175.00 to 213.40 & 0.017 \\
\hline $\mathrm{AC}(\mathrm{mm})$ & $177.08 \pm 16.15$ & 156.00 to 198.00 & $171.36 \pm 16.12$ & 150.82 to 194.45 & $<0.0001$ \\
\hline Femur length (mm) & $37.33 \pm 3.86$ & 32.50 to 42.40 & $35.93 \pm 3.78$ & 30.72 to 41.10 & $<0.0001$ \\
\hline Tibia length (mm) & $32.92 \pm 3.42$ & 28.30 to 37.30 & $31.90 \pm 3.53$ & 27.12 to 36.92 & 0.001 \\
\hline Fibula length (mm) & $32.76 \pm 3.33$ & 28.35 to 37.00 & $31.71 \pm 3.27$ & 26.88 to 36.00 & 0.001 \\
\hline Humerus length (mm) & $35.39 \pm 3.34$ & 31.00 to 39.70 & $34.40 \pm 3.24$ & 29.94 to 38.70 & 0.001 \\
\hline Radius length (mm) & $30.34 \pm 2.94$ & 26.70 to 34.00 & $29.38 \pm 2.70$ & 25.70 to 32.46 & $<0.0001$ \\
\hline Ulna length (mm) & $32.92 \pm 3.21$ & 28.80 to 37.00 & $32.07 \pm 3.14$ & 28.00 to 36.30 & 0.004 \\
\hline Estimated FBW (g) & $508.75 \pm 116.48$ & 364.00 to 666.00 & $470.74 \pm 107.31$ & 343.60 to 608.20 & $<0.0001$ \\
\hline CTAR & $0.22 \pm 0.12$ & 0.18 to 0.25 & $0.21 \pm 0.03$ & 0.18 to 0.25 & 0.753 \\
\hline CTCR & $0.46 \pm 0.06$ & 0.42 to 0.50 & $0.46 \pm 0.03$ & 0.43 to 0.50 & 0.131 \\
\hline UA PI & $1.16 \pm 0.22$ & 0.93 to 1.40 & $1.33 \pm 0.34$ & 0.99 to 1.91 & $<0.0001$ \\
\hline UA RI & $0.69 \pm 0.08$ & 0.60 to 0.78 & $0.74 \pm 0.09$ & 0.64 to 0.86 & $<0.0001$ \\
\hline MCA PI & $1.59 \pm 0.27$ & 1.26 to 1.90 & $1.48 \pm 0.24$ & 1.18 to 1.82 & $<0.0001$ \\
\hline MCA RI & $0.81 \pm 0.08$ & 0.72 to 0.91 & $0.79 \pm 0.65$ & 0.71 to 0.87 & 0.008 \\
\hline MCA/UA PI ratio & $1.41 \pm 0.34$ & 1.02 to 1.79 & $1.19 \pm 0.38$ & 0.66 to 1.67 & $<0.0001$ \\
\hline MCA/UA RI ratio & $1.19 \pm 0.18$ & 0.99 to 1.40 & $1.09 \pm 0.18$ & 0.85 to 1.30 & $<0.0001$ \\
\hline
\end{tabular}

AC, abdominal circumference; BPD, biparietal diameter; CTAR, cardiothoracic area ratio; CTCR, cardiothoracic circumference ratio; FBW, fetal body weight; HC, head circumference; MCA, middle cerebral artery; MCA/UA PI ratio, ratio of middle cerebral artery resistance index to umbilical artery pulsatility index; MCA/UA RI ratio, ratio of middle cerebral artery resistance index to umbilical artery resistance index; NBL, nasal bone length; PI, pulsatility index; RI, resistance index; SD, standard deviation; UA, umbilical artery; VSD, ventricular septal defect.

proportion of VSD cases in the study population was $4.66 \%$, which is higher than the previously reported rates. A possible reason for this discrepancy is natural fetal loss or pregnancy termination because of abnormalities or malformations of the fetus. Research showed that $74 \%$ of isolated fetal VSDs close spontaneously prior to birth [41].

One of the major limitations of this study was the potential for selection bias caused by the use of a screened hospital-based population. However, because of our relatively large sample size, we were able to achieve statistically significant conclusions. Secondly, we did not explicitly consider the sensitivity and specificity of the screening tests. Although the agreement of interobserver reliability seemed acceptable, nondifferential misclassification-bias identification still could have occurred. Thirdly, from the screening cost viewpoint, it is very difficult to follow all of the study cases with postnatal echocardiography. Finally, we collected our measurements at a single point in time, which could have eliminated the influence of various longterm demographic or biochemical factors on the risk of VSDs. Further longitudinal investigations to confirm our study findings are warranted.

\section{Conclusions}

In this study we evaluated the NBL, MCA PI, and UA PI of fetuses with VSDs in the late-second trimester of pregnancy. Our results indicate that the evaluation of

Table 5 Multiple logistic regression of associated factors for ventricular septal defects among screened fetuses $(n=2,661)$

\begin{tabular}{lccccc}
\hline Variable & $\boldsymbol{\beta}$ & $\mathrm{SE}$ & \multicolumn{2}{c}{ Ventricular septal defects (yes vs. no) } & 95\% confidence interval \\
\cline { 4 - 5 } & & & 0.69 & 0.55 to 0.87 & \\
\hline NBL & -0.37 & 0.12 & 8.10 & 4.31 to 15.21 & 0.001 \\
UA PI & 2.09 & 0.32 & 0.25 & 0.12 to 0.54 & $<0.0001$ \\
MCA PI & -1.37 & 0.38 & $<0.0001$
\end{tabular}

MCA, middle cerebral artery; NBL, nasal bone length; PI, pulsatility index; UA, umbilical artery; SE, standard error. 
these parameters provides an appropriate method for the screening of fetal VSDs.

\section{Abbreviations}

BPD: biparietal diameter; AC: abdominal circumference; CHD: congenital heart disease; FBW: fetal body weight; GA: gestational age; MCA: middle cerebral artery; NBL: nasal bone length; PI: pulsatility index; Rl: resistance index; UA: umbilical artery; VSD: ventricular septal defect.

\section{Competing interests}

The authors declare that they have no competing interests.

\section{Authors' contributions}

W-HC and T-HT executed the study and drafted the manuscript. M-CH, R-CC, and T-HT participated in the study design and performed the statistical analyses. M-CH, R-CC, X-MX, and C-LW envisioned the study and coordinated drafting the manuscript. All authors read and approved the final version of the manuscript

\section{Acknowledgements}

This study was supported by the grants from the National Science Council (NSC-98-2314-B-002-MY3) and Cheng-Hsin General Hospital (100-39, 101-59, 102-39).

\section{Author details}

'Department of Biomedical Imaging and Radiological Sciences, School of Biomedical Science and Engineering, National Yang-Ming University, 112 Taipei, Taiwan. ${ }^{2} 1$ st Clinical Medical College, Jinan University, 510632 Guangzhou, China. ${ }^{3}$ Department of Obstetrics and Gynecology, Chung Shan Hospital, 106 Taipei, Taiwan. ${ }^{4}$ Division of Cardiology, Department of Medicine, Cheng-Hsin General Hospital, 112 Taipei, Taiwan. ${ }^{5}$ Department of Radiology, Taipei City Hospital, 100 Taipei, Taiwan. ${ }^{6}$ Department of Obstetrics and Gynecology, The 3rd Affiliated Hospital of Sun Yat-Sen University, Guangzhou, China. ${ }^{7}$ Department of Medical Research and Education, Cheng Hsin General Hospital, No. 45, Cheng-Hsin Street, 112 Taipei, Taiwan. ${ }^{8}$ Faculty of Public Health, School of Medicine, Fu-Jen Catholic University, 24205 New Taipei City, Taiwan.

\section{Received: 15 June 2013 Accepted: 8 January 2014}

Published: 24 January 2014

\section{References}

1. Yang $X Y$, Li XF, Lü XD, Liu YL: Incidence of congenital heart disease in Beijing, China. Chin Med J 2009, 122:1128-1132

2. Capozzi G, Caputo S, Pizzuti R, Martina L, Santoro M, Santoro G, Sarubbi B, lacono C, D'Alto M, Bigazzi MC, Pacileo G, Merlino E, Caianiello G, Russo MG, Calabrò R: Congenital heart disease in live-born children: incidence, distribution, and yearly changes in the Campania Region. J Cardiovasc Med 2008, 9:368-374.

3. Hoffman Jl, Kaplan S: The incidence of congenital heart disease. J Am Coll Cardiol 2002, 39:1890-1900.

4. Ozkutlu S, Akça T, Kafalı G, Beksaç S: The results of fetal echocardiography in a tertiary center and comparison of low- and high-risk pregnancies for fetal congenital heart defects. Anadolu Kardiyol Derg 2010, 10:263-269.

5. Paladini D, Russo M, Teodoro A, Pacileo G, Capozzi G, Martinelli P, Nappi C, Calabrò R: Prenatal diagnosis of congenital heart disease in the Naples area during the years 1994-1999 - the experience of a joint fetalpediatric cardiology unit. Prenat Diagn 2002, 22:545-552.

6. Stoll C, Garne E, Clementi M: Evaluation of prenatal diagnosis of associated congenital heart diseases by fetal ultrasonographic examination in Europe. Prenat Diagn 2001, 21:243-252.

7. Yagel S, Silverman NH, Gembruch U: Fetal Cardiology: Embryology, Genetics, Physiology, Echocardiographic Evaluation, Diagnosis, and Perinatal Management of Cardiac Diseases. 2nd edition. New York: Informa Healthcare USA, Inc.; 2009

8. Kovalchin JP, Silverman NH: The impact of fetal echocardiography. Pediatr Cardiol 2004, 25:299-306.

9. Verheijen PM, Lisowski LA, Stoutenbeek P, Hitchcock JF, Brenner JI, Copel JA, Kleinman CS, Meijboom EJ, Bennink GB: Prenatal diagnosis of congenital heart disease affects preoperative acidosis in the newborn patient. $J$ Thorac Cardiovasc Surg 2001, 121:798-803.
10. Rustico MA, Benettoni A, D'Ottavio G, Maieron A, Fischer-Tamaro I, Conoscenti G, Meir Y, Montesano M, Cattaneo A, Mandruzzato G: Fetal heart screening in low-risk pregnancies. Ultrasound Obstet Gynecol 1995, 6:313-319.

11. Canale JM, Sahn DJ, Allen HD, Goldberg SJ, Valdes-Cruz LM, Ovitt TW: Factors affecting real-time, cross-sectional echocardiographic imaging of perimembranous ventricular septal defects. Circulation 1981, 63:689-697.

12. Chaoui R, Bollmann R: Fetal color Doppler echocardiography. Part 1: general principles and normal findings. Ultraschall Med 1994, 15:100-104.

13. Chaoui R, McEwing R: Three cross-sectional planes for fetal color Doppler echocardiography. Ultrasound Obstet Gynecol 2003, 21:81-93.

14. Quiñones MA, Otto CM, Stoddard M, Waggoner A, Zoghbi WA: Doppler Quantification Task Force of the Nomenclature and Standards Committee of the American Society of Echocardiography. Recommendations for quantification of Doppler echocardiography: a report from the Doppler Quantification Task Force of the Nomenclature and Standards Committee of the American Society of Echocardiography. J Am Soc Echocardiogr 2002, 15:167-184.

15. Chaoui R, Bollmann R: Fetal color Doppler echocardiography. Part 2: abnormalities of the heart and great vessels. Ultraschall Med 1994, 15:105-111.

16. DeVore GR, Horenstein J, Siassi B, Platt LD: Fetal echocardiography. VII. Doppler color flow mapping: a new technique for the diagnosis of congenital heart disease. Am J Obstet Gynecol 1987, 156:1054-1064.

17. Marx GR: Doppler color flow echocardiography: indispensable application to congenital heart disease. Echocardiography 1995, 12:413-424.

18. Bahtiyar MO, Dulay AT, Weeks BP, Friedman AH, Copel JA: Prenatal course of isolated muscular ventricular septal defects diagnosed only by color Doppler sonography: single-institution experience. J Ultrasound Med 2008, 27:715-720.

19. Khoo NS, van Essen P, Richardson M, Robertson T: Effectiveness of prenatal diagnosis of congenital heart defects in South Australia: a population analysis 1999-2003. Aust N Z J Obstet Gynaecol 2008, 48:559-563.

20. Meise C, Germer U, Gembruch U: Arterial Doppler ultrasound in 115 second- and third-trimester fetuses with congenital heart disease. Ultrasound Obstet Gynecol 2001, 17:398-402.

21. Kaltman JR, Di H, Tian Z, Rychik J: Impact of congenital heart disease on cerebrovascular blood flow dynamics in the fetus. Ultrasound Obstet Gynecol 2005, 25:32-36.

22. Guorong L, Shaohui L, Peng J, Huitong L, Boyi L, Wanhong X, Liya L: Cerebrovascular blood flow dynamic changes in fetuses with congenital heart disease. Fetal Diagn Ther 2009, 25:167-172.

23. Chiu WH, Tung TH, Chen YS, Wang WH, Lee SM, Horng SC, Yang FY: Normative curves of fetal nasal bone length for the ethnic Chinese population. Ir J Med Sci 2011, 180:73-77.

24. Nisbet D, Robinson H, Halliday J, de CL: Australian Society of Ultrasound in Medicine (ASUM) Policy Statement on normal ultrasonic fetal measurements. Aust N Z J Obstet Gynaecol 2002, 42:101-103.

25. Goldstein RB, Filly RA, Simpson G: Pitfalls in femur length measurements. J Ultrasound Med 1987, 6:203-207.

26. Hadlock FP: Sonographic estimation of fetal age and weight. Radio/ Clin North Am 1990, 28:39-50.

27. International Society of Ultrasound in Obstetrics \& Gynecology: Cardiac screening examination of the fetus: guidelines for performing the 'basic' and 'extended basic' cardiac scan. Ultrasound Obstet Gynecol 2006, 27:107-113.

28. Rychik J, Ayres N, Cuneo B, Gotteiner N, Hornberger L, Spevak PJ, van der Veld M: American Society of Echocardiography guidelines and standards for performance of the fetal echocardiogram. J Am Soc Echocardiogr 2004, 17:803-810.

29. Lethor JP, Marçon F, de Moor M, King ME: Physiology of ventricular septal defect shunt flow in the fetus examined by color Doppler M-mode. Circulation 2000, 101:E93

30. Merz E: Ultrasound in Obstetrics and Gynecology. 2nd edition. Germany: Thieme; 2005.

31. Mari G, Deter RL, Carpenter RL, Rahman F, Zimmerman R, Moise KJ Jr, Dorman KF, Ludomirsky A, Gonzalez R, Gomez R, Oz U, Detti L, Copel JA, Bahado-Singh R, Berry S, Martinez-Poyer J, Blackwell SC: Noninvasive diagnosis by Doppler ultrasonography of fetal anemia due to maternal red-cell alloimmunization. Collaborative Group for Doppler Assessment of the Blood Velocity in Anemic Fetuses. N Engl J Med 2000, 342:9-14. 
32. Hsieh FY, Block DA, Larsen MD: A simple method of sample size calculation for linear and logistic regression. Stat Med 1998, 17:1623-1634.

33. McQuillen PS, Miller SP: Congenital heart disease and brain development. Ann N Y Acad Sci 2010, 1184:68-86.

34. Mari G, Deter RL: Middle cerebral artery flow velocity waveforms in normal and small-for-gestational-age fetuses. Am J Obstet Gynecol 1992, 166:1262-1270.

35. Vyas S, Nicolaides KH, Bower S, Campbell S: Middle cerebral artery flow velocity waveforms in fetal hypoxaemia. Br J Obstet Gynaecol 1990, 97:797-803.

36. Al-Jarallah AS: Down's syndrome and the pattern of congenital heart disease in a community with high parental consanguinity. Med Sci Monit 2009, 15:409-412.

37. Monni G, Zoppi MA, Ibba RM, Floris M, Manca F, Axiana C: Nuchal translucency and nasal bone for trisomy 21 screening: single center experience. Croat Med J 2005, 46:786-791.

38. Bunduki V, Ruano R, Miguelez J, Yoshizaki CT, Kahhale S, Zugaib M: Fetal nasal bone length: reference range and clinical application in ultrasound screening for trisomy 21. Ultrasound Obstet Gynecol 2003, 21:156-160.

39. Meberg A, Otterstad JE, Frøland G, Søarland S, Nitter-Hauge S: Increasing incidence of ventricular septal defects caused by improved detection rate. Acta Paediatr 1994, 83:653-657.

40. Sands AJ, Casey FA, Craig BG, Dornan JC, Rogers J, Mulholland HC Incidence and risk factors for ventricular septal defect in 'low risk' neonates. Arch Dis Child Fetal Neonatal Ed 1999, 81:61-63.

41. Drose JA: Fetal Echocardiography. 2nd edition. Philadelphia: Saunders; 2010.

doi:10.1186/2047-783X-19-3

Cite this article as: Chiu et al:: Prenatal ultrasonography and Doppler sonography for the clinical investigation of isolated ventricular septal defects in a late second-trimester population. European Journal of Medical Research 2014 19:3.

\section{Submit your next manuscript to BioMed Central and take full advantage of:}

- Convenient online submission

- Thorough peer review

- No space constraints or color figure charges

- Immediate publication on acceptance

- Inclusion in PubMed, CAS, Scopus and Google Scholar

- Research which is freely available for redistribution 